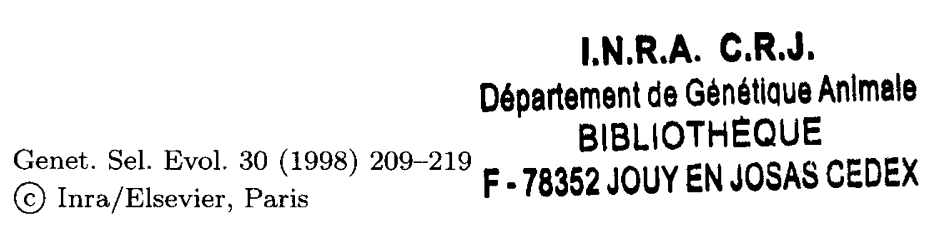

\title{
The chicken as a model to study microchromosomes in birds: a review
}

\author{
Valérie Fillon \\ Laboratoire de génétique cellulaire, Institut national de la recherche agronomique, \\ BP27, 31326 Castanet-Tolosan cedex, France
}

(Received 17 December 1997; accepted 22 April 1998)

\begin{abstract}
The typical avian karyotype is composed of a few macrochromosomes and around 60 indistinguishable small microchromosomes. Due to its economic importance, the chicken is the avian species for which cytogenetic and genetic maps are the most developed. Based on these genome studies, it has been shown that the chicken microchromosomes are carriers of dense genetic information. Indeed, they probably bear at least $50 \%$ of the genes and exhibit high recombination rates. Because of the presence of microchromosomes, the genetic size of the chicken genome seems higher than first estimated and could reach more than $4000 \mathrm{cM}$ for $1200 \mathrm{Mb}$. Thus, it is worth developing the microchromosome map. From an evolutionary point of view, comparative mapping data raise many questions about the origin of microchromosomes. They could be ancestral chromosomes, from which large chromosomes formed by fusions, or conversely they could be the result of the splitting of macrochromosomes. (c) Inra/Elsevier, Paris
\end{abstract}

microchromosome / chicken / genomic map / recombination rate

Résumé - La Poule comme modèle d'étude des microchromosomes d'oiseaux : une revue. Le caryotype aviaire typique est constitué de quelques macrochromosomes et d'environ soixante microchromosomes punctiformes et indiscernables les uns des autres. Du fait de son importance économique, la Poule est l'espèce d'oiseaux dont les cartes génétique et cytogénétique sont les plus avancées. Ces études ont permis de montrer que les microchromosomes contiennent une information génétique dense. En effet, ils portent probablement au moins $50 \%$ des gènes et ils ont des taux de recombinaison élevés. Du fait de la présence des microchromosomes, la taille génétique attendue pour le génome de la Poule est d'au moins $4000 \mathrm{cM}$ pour $1200 \mathrm{Mb}$. Il apparaît donc important de densifier la carte génétique des microchromosomes. Du point de vue évolutif, les données de cartographie comparée soulèvent de nombreuses questions quant à l'origine des microchromosomes. Ils pourraient être des caractères ancestraux ayant permis la formation des grands chromosomes par fusion, ou au contraire être le résultat de plusieurs fissions chromosomiques. (c) Inra/Elsevier, Paris microchromosome / poule / carte génomique / taux de recombinaison

E-mail: vfillon@toulouse.inra.fr 


\section{INTRODUCTION}

Microchromosomes were discovered in the first chicken chromosome preparations and were then considered as small genetically inert accessory elements, totally heterochromatic, without any gene or centromere and constituting a reserve of nucleic acids for chromosomal replication [57]. Later observations, demonstrating their constant number in the karyotype of different studied species, led to their being considered as genuine chromosomes $[41,58,78]$, although they were thought to exhibit no recombination in order to preserve ancestral linkage groups [73].

Birds are the vertebrates that have the greatest number of microchromosomes. The typical avian karyotype is composed of around 80 chromosomes separated into two classes: a few distinguishable macrochromosomes and a much higher number of small microchromosomes, visualized as dots on metaphase preparations and usually classified by decreasing size [17]. Except for the Falconiformes and particularly the Accipitridae family which has no more than three to six microchromosome pairs [24], the average number of microchromosomes is $60[17,77]$. Depending on the species, the borderline between both groups is not always clear. The usual criteria used to define microchromosomes are mainly their size (which varies according to authors between 0.5 and $1.5 \mu \mathrm{m}$ [44]), the impossibility of distinguishing them from each other and of defining the centromere position [77].

Because of its economic importance, the chicken is the avian species for which cytogenetic and genetic maps are the most developed and important international efforts are under way to build up a complete genome coverage, making it a reference for the detailed study of bird genomes.

\section{THE CHICKEN KARYOTYPE}

Although the boundary between macro- and microchromosomes varies according to authors, the actual standard karyotype description by GTG- and RBG-banding for the chicken, established by the International Committee for the Standardization of the Avian Karyotype, concerns eight pairs of macrochromosomes and sex chromosomes Z and W (ICSAK, 1993: K. Ladjali, J.J. Bitgood, R.N. Schoffner and F.A. Ponce de Leon; [42]). The remaining 30 pairs of chromosomes are referred to as microchromosomes and only an approximate size can usually be given for individual descriptions. Indeed, due to their smaller size and lower degree of chromatin compaction [68], it is impossible to obtain characteristic banding patterns for each pair. However, by using DAPI or chromomycin A3 staining, it has been suggested that most of the microchromosomes had lower $(\mathrm{A}+\mathrm{T})$ and higher $(\mathrm{G}+\mathrm{C})$ contents than the macrochromosomes $[2,30]$. This specific structure was confirmed by the fact that the microchromosomes replicate earlier $[63,71]$ and also that a high proportion of $\mathrm{CpG}$ islands is located on them [47]. The only chicken microchromosome pair that has been given a number is the one bearing the nucleolar organizer region, visible after silver staining, and the major histocompatibility complex (MHC). It is usually referred to as chromosome number 16 $[2,5]$. More recently, electron microscopic analyses on chicken synaptonemal complexes enabled confirmation that microchromosomes account for $30 \%$ of 
the chicken genome and determination of the position of the centromeres. Most microchromosomes were thus found to be acrocentric [37]. The physical size of the chicken genome is $1200 \mathrm{Mb}$ : the mean size for chicken macrochromosomes is around 130 Mbases, and only 12.5 Mbases for microchromosomes, with the smallest one estimated to be as small as 7 Mbases [6].

\section{THE CHICKEN GENOMIC MAP}

Chicken genetic maps are composed of around 650 molecular markers $[13$, 43]. The genetic size is between 2500 and $3400 \mathrm{cM}$. They are composed of a small number of large linkage groups that have been assigned to macrochromosomes, and numerous small linkage groups or independent markers probably corresponding to microchromosomes, but for which a cytogenetic localization still needs to be defined $[7,9,13,15,21,43]$. Recognizing each individual microchromosome is essential to allow a precise localization of genes and markers, leading to completed genetic maps. For this purpose, a collection of large insert $\mathrm{BAC}$ (bacterial artificial chromosome) and PAC (bacteriophage P1 artificial chromosome) clones [80] to be used as microchromosome tags for identification in two-colour FISH experiments has been developed [29] enabling the individual characterization of 16 microchromosome pairs. These clones have also permitted 14 linkage group assignments (Morisson, pers. comm.). The identification of microchromosome pairs leading to the integration of the genetic and cytogenetic maps is the first step towards a better knowledge of microchromosomes, especially with regards their genetic composition and their recombination rates.

\section{THE GENETIC COMPOSITION OF MICROCHROMOSOMES}

\subsection{The density of genes}

Despite their very small size, microchromosomes seem to hold many genes. $\mathrm{CpG}$ islands, which are short unmethylated CpG-rich sequences located towards the 5 end of many vertebrate genes [1], are enriched on microchromosomes [47]. This suggests the presence of a higher gene density than on macrochromosomes. Indeed, more than half of the mapped genes have been localized on chicken microchromosomes, confirming their genetic importance [62], whereas less than $40 \%$ of the genetically mapped genes are localized on macrochromosomes 1-4 which represent $50 \%$ of the chicken genome [Chick GBase (http://www.ri.bbsrc.ac.uk/chickmap/chickgbase/chickgbase.html)]. Moreover, it has been demonstrated for a few genes that the size of chicken intronic sequences is shorter than for human homologues [32, 34]. Microchromosome 16 confirms this high density of genes as it carries the rDNA genes [2], major histocompatibility complexes $B[5,26]$ and $R f p-Y$ [28], the lectin genes [4] and a few other genes (ChickGBase). This high gene density demonstrates that it is worth developing the genetic map of microchromosomes.

\subsection{The distribution of repeated sequences}

Highly repeated sequences correspond to $36 \%$ of the human genome and $12 \%$ of the chicken genome [6]. It is thought that the chicken genome and 
especially microchromosomes lack repetitive DNA because of loss or nonacquisition of such sequences. However, constitutive heterochromatin is located essentially on chromosomes $\mathrm{Z}$ or $\mathrm{W}$ and some microchromosomes, whereas macrochromosomes are weakly stained in C-banding studies [11, 61, 74]. Moreover, repeated sequences enriched on microchromosomes have been cloned. The first one, isolated from chicken, represents $10 \%$ of the genome and probably concerns centromeric heterochromatin [45]. The second corresponds to $5 \%$ of the turkey genome and is located on one third of the microchromosomes [46]. Some clones showing repeated hybridization patterns localized specifically on microchromosome pairs have also been reported [29]. Thus, despite their high gene density and their small size, microchromosomes do not lack repeated DNA.

Microsatellites are repeated sequences of particular value for genome mapping as they have been shown to be highly polymorphic in the chicken $[14,18]$. But the frequency of different types of microsatellites differs between birds and mammals. The frequency of dinucleotides $(\mathrm{CA}) \mathrm{n}$ in birds is one fifth of that in mammals. There are $7000-9000$ (CA)n in the chicken genome, spread every $136-150 \mathrm{~kb}$, instead of every $30 \mathrm{~kb}$ in human [53,65]. Moreover, they seem to be concentrated on macrochromosomes based on PRINS experiments [65]. The low proportion of $(\mathrm{CA}) \mathrm{n}$ in the chicken genome was confirmed by high stringency screening of PAC and BAC libraries (Morisson, pers. comm.). However, about one third of these clones were localized on microchromosomes by FISH, suggesting homogeneous distribution of $(\mathrm{CA}) \mathrm{n}$ microsatellites between macro- and microchromosomes. It would be interesting to screen for tri- or tetra-nucleotide repeats as they seem more frequent in the chicken genome [53].

\section{THE RECOMBINATION RATE OF MICROCHROMOSOMES}

At least one chiasma per chromosome is needed regardless of its size [12, $27,36]$. Indeed, chiasma analyses on chicken lampbrush chromosomes demonstrated that in microchromosomes one or two crossing-over events may occur: on average one per 11-12 Mb, whereas avian macrochromosomes have one crossing-over per $30 \mathrm{Mb}[66,69,70]$. Despite their small size, microchromosomes would thus have an associated linkage group of at least $50 \mathrm{cM}$ and therefore a high genetic to physical distance ratio. Thus, the two genetically independent major histocompatibility complexes $B$ and $R f p-Y$ [51,52] have been located on the same microchromosome 16 , demonstrating the occurrence of recombinations [28]. Moreover, based on mapping of anonymous molecular markers, it has recently been shown in several cases that the linkage groups corresponding to microchromosomes are more than $50 \mathrm{cM}$ long (Morisson, pers. comm.).

Due to the presence of microchromosomes, but also because of the great number of chromosomes, the recombination potential of the chicken genome is high. Indeed, the segregation of parental chromosomes during meiosis allows a mixing of the genetic material. The recombination index (RI) calculated ( $\mathrm{RI}=\mathrm{n}+\mathrm{TC}$, where $\mathrm{n}$ is the number of bivalents and TC the total number of chiasmatas) is $90-100$ in birds, whereas it is on average 50 in mammals [68]. Moreover, the domestic species studied (dog, cat, pig, cattle, etc.) tend to have higher chiasma frequencies [8]. These values could be due to the 
intense selection effort on small livestock populations sometimes changing allelic associations between closely linked genes, and creating new haplotypes. According to the values found in the chicken, the potential response of avian genomes to selection could be very high. However, if the recombination rate is very high, saturated genetic maps would be necessary to have very close markers available each time in order to permit a molecular marker-assisted selection. The current genetic maps contain around 650 genetic markers [13]. However, the genome coverage is not achieved as $10 \%$ of new mapped markers are still unlinked. Moreover, the genetic size of microchromosomes is high compared to their physical size. We may still expect a total genetic size as large as 4000 cM for $1200 \mathrm{Mb}$. Thus, to detect QTLs, 1000-1200 markers will be needed on the map, so as to be able to choose a high quality subset of 200-400 markers $[20,21]$. Thus, more molecular markers should be developed, especially for microchromosomes.

\section{THE EVOLUTIONARY MEANING OF MICROCHROMOSOMES}

Some regions of conserved syntenies, involving 2-6 loci, have already been described between birds and mammals, although they diverged some 300 million years ago $[9,10]$. Most of them concern macrochromosomes. For example, chicken chromosome 1 corresponds to human chromosomes 11, 12, 15 and 17 [40], and some genes of the chicken chromosome $7 q$ are conserved on human chromosome $2 \mathrm{q}[31,33]$. Two cases involving chicken microchromosomes have also been reported. The first syntenic group is composed of three genes [35, 67] located on a $25-\mathrm{Mb}$ microchromosome and on human chromosome $15 \mathrm{q}$, probably in the same order [35]. The second example shows that human chromosome $17 \mathrm{q}$ corresponds to at least four chicken chromosomes, including chromosome $\mathrm{Z}$ $[19,38]$, chromosome 1 [72] and two different microchromosomes [60]. This suggests that numerous rearrangements have occurred and raises interesting questions about the evolution of vertebrate genomes, such as whether the microchromosomes originate from splitting large chromosomes or the macrochromosomes originate from aggregation of small ones. Microchromosomes may contain syntenic groups well conserved within vertebrates. Avian microchromosomes may represent ancient genome structures that have aggregated together in other species to give rise through evolution to larger structures. If they have not been rearranged with other chromosomes during avian evolution, they might carry ancient gene combinations and their study would give insights into the general evolution of vertebrate karyotypes. The current progress in mapping chicken genes will generate more comparative mapping data, and will enable us to test this hypothesis by further estimating the degree of rearrangements between mammals and birds.

Microchromosomes are also present in lower numbers in a few other vertebrates (fish, batracians, reptiles) and tend to disappear completely in mammals [68]. According to Rodionov [68], it might be tempting to consider them as ancestral chromosomes although they are very rare in fish and batracians. Indeed, they could have been inherited from a common ancestor of the vertebrates, as they can be encountered in primitive orders such as cartilaginous fish [59, 75], salamanders [55] or monotreme [79]. Moreover, general features of 
bird karyotypes seem very well conserved between ratites and carinatas [17]. The appearance of microchromosomes could precede bird adaptative radiation at the end of the Jurassic, beginning of the Cretaceous [16]. However, crocodilians [39], which are closer to birds, have karyotypes without any microchromosome, as do frogs [54]. In reptiles [48, 64, 76] and amphibians [55], only a small number of chromosomes can be thought to be microchromosomes. We note as well that most of the bird species show a typical karyotype with around 60 microchromosomes, although the Accipitridae have only three to six pairs of microchromosomes [22, 23, 24]. In Ciconiiformes, there is an important reduction in the number of chromosomes (50-60) and only around 20 microchromosomes [3,25]. Furthermore, there is an increase in the number of chromosomes and microchromosomes in the Coraciiformes, where more than 100 microchromosomes are found $[17,77]$.

At the current level of knowledge, there are no data to explain the high number of microchromosomes in bird karyotypes. If it is the ancestral situation, we could imagine that mammalian chromosomes have been formed by the fusion of microchromosomes and/or the acquisition of non-coding DNA sequences. When the number of macrochromosomes increases, the number of microchromosomes diminishes; higher proportions of acrocentric chromosomes are found in species with larger numbers of microchromosomes, and more metacentric or submetacentric macrochromosomes are found in species with fewer microchromosomes [77]. Robertsonian fusions or translocations could occur between chromosomes, leading to the formation of two very distinct groups of chromosomes $[44,68$, 77 . The presence of many telomeric, pericentromeric or interspersed sequences in the chicken genome could be the evidence for such chromosomal rearrangements [56]. However, some species (among Passeriformes) have only a telomeric distribution of (TTAGGG)n sequences [50]. This sequence, very well conserved in vertebrates, is located on every telomere, which is also true for microchromosomes [49]. In reptiles, fish and amphibians, hybridization signals were also found in pericentromeric or interstitial regions for some species [50]. But microchromosomes could also be the result of chromosome fissions, in which case (TTAGGG)n interstitial sites would be interpreted as being regions existing prior to the formation of new telomeres [50].

\section{CONCLUSION}

Microchromosomes are genuine chromosomes, probably bearing at least $50 \%$ of the genes in the chicken and exhibiting high recombination rates. It makes sense to approach the chicken genome by developing the genetic map of microchromosomes. Microsatellite sequences seem to be uniformly spread within the genome, and could provide new molecular markers even if they are less frequent than in mammals.

Although microchromosomes carry dense genetic information, they also have several families of repeated DNA sequences. Further studies on specific chromosome repeated sequences could give valuable information on the organization of microchromosomes, especially the centromeric sequences. In the longer term, microdissection of chromosomes or large scale sequencing could enable us to refine our knowledge of specific microchromosomal regions. 
Despite all the comparative data available, it is still difficult to understand the evolutionary meaning of microchromosomes. The presence of conserved segments in mammals and birds allows the reconstitution of some chromosome rearrangements and the discovery of probably ancient groups of genes. The remaining question is the direction of chromosome evolution. Microchromosomes could be ancestral, at the origin of large chromosomes by fusion or conversely originate from macrochromosomes by splitting.

\section{REFERENCES}

[1] Antequera F., Bird A., Number of CpG islands and genes in human and mouse, Proc. Natl. Acad. Sci. USA 90 (1993) 11995-11999.

[2] Auer H., Mayr B., Lambrou M., Schleger W., An extended chicken karyotype, including the NOR chromosome, Cytogenet. Cell Genet. 45 (1987) 218-221.

[3] Belterman R.H.R., De Boer L.E.M., A karyological study of 55 species of birds, including karyotypes of 39 species new to cytology, Genetica 65 (1984) $39-82$.

[4] Bernot A., Zoorob R., Auffray C., Linkage of a new member of the lectin supergene family to chicken MHC genes, Immunogenetics 39 (1994) 221-229.

[5] Bloom S.E., Bacon L.D., Linkage of the major histocompatibility (B) complex and the nucleolar organizer in the chicken, J. Hered. 76 (1985) 146-154.

[6] Bloom S.E., Delany M.E., Muscarella D.E., Constant and variable features of the avian chromosomes, in: Etches R.J., Gibbins A.M.V. (Eds.), Manipulation of the Avian Genome, CRC press, Guelph, Canada, 1993, pp. 39-59.

[7] Bumstead N., Palyga J., A preliminary linkage map of the chicken genome, Genomics 13 (1992) 690-697.

[8] Burt A., Bell G., Mammalian chiasma frequencies as a test of two theories of recombination, Nature 326 (1987) 803-805.

[9] Burt D.W., Bumstead N., Bitgood J.J., Ponce de Leon F.A., Crittenden L.B., Chicken genome mapping: a new era in avian genetics, Trends Genet. 11 (1995) 190-194.

[10] Burt D.W., Jones C.T., Morrice D.R., Taton I.R., Mapping the chicken genome - An aid to comparative studies, Anim. Genet. 27 (suppl. 2) (1996) 66.

[11] Carlenius C., Ryttman H., Tegelström H., Jansson H., R-, G- and C-banded chromosomes in the domestic fowl (Gallus domesticus), Hereditas 94 (1981) 61-66.

[12] Carpenter A.T.C., Chiasma function, Cell 77 (1994) 959-962.

[13] Cheng H.H., Mapping the chicken genome, Poult. Sci. 76 (1997) 1101-1107.

[14] Cheng H.H.,Crittenden L.B., Microsatellite markers for genetic mapping in the chicken, Poult. Sci. 73 (1994) 539-546.

[15] Cheng H.H., Levin I., Vallejo R.L., Khatib H., Dodgson J.B., Crittenden L.B., Hillel J., Development of a genetic map of the chicken with markers of high utility, Poult. Sci. 74 (1995) 1855-1874.

[16] Chiappe L.M., The first 85 million years of avian evolution, Nature 378 (1995) 349-355.

[17] Christidis L., Animal Cytogenetics, 4 chordata 3, Aves, Gebrüder Borntraeger, Berlin, 1990.

[18] Crooijmans R.P.M.A., Van Kampen A.J.A., Van der Poel J.J., Groenen M.A.M., Highly polymorphic microsatellite markers in poultry, Anim. Genet. 24 (1993) 441-443. 
[19] Crooijmans R.P.M.A., Van der Poel J.J., Groenen M.A.M., Functional genes mapped on the chicken genome, Anim. Genet. 26 (1995) 73-78.

[20] Crooijmans R.P.M.A., Groen A.B.F., Van Kampen A.J.A., Van des Beek S., Van der Poel J.J., Groenen M.A.M., Microsatellite polymorphism in commercial broiler and layer lines estimated using pooled blood samples, Poult. Sci. 75 (1996) 904-909.

[21] Crooijmans R.P.M.A., Van Oers P.A.M., Strijk J.A., Van der Poel J.J., Groenen M.A.M., Preliminary linkage map of the chicken (Gallus gallus domesticus) genome based on microsatellite markers, 77 new markers mapped, Poult. Sci. 75 (1996) 746-754.

[22] De Boer L.E.M., Karyological heterogeneity in the Falconiformes (Aves), Experentia 31 (1975) 1135-1139.

[23] De Boer L.E.M., The somatic chromosome complements of 16 species of Falconiformes (Aves) and the karyological relationships of the order, Genetica 65 (1976) 77-113.

[24] De Boer L.E.M., Sinoo R.P., A karyological study of Accipitridae (Aves: Falconiformes), with karyotypic descriptions of 16 species new to cytology, Genetica 65 (1984) 89-107.

[25] De Boer L.E.M., Van Brink J.M., Cytotaxonomy of the Ciconiiformes (Aves), with karyotypes of eight species new to cytology, Cytogenet. Cell Genet. 34 (1982) 19-34.

[26] Dominguez-Steglich M., Auffray C., Schmid M., Linkage of the chicken MHC to the nucleolus organiser region visualised using non-isotopic in situ hybridization, J. Hered. 82 (1991) 503-505.

[27] Dutrillaux B., Le rôle des chromosomes dans l'évolution : une nouvelle interprétation, Ann. Génét. 29 (1986) 69-75.

[28] Fillon V., Zoorob R., Yerle M., Auffray C., Vignal A., Mapping of the genetically independant chicken major histocompatibility complexes $B @$ and $R F P$ $Y @$ to the same microchromosome by two-color fluorescent in situ hybridization, Cytogenet. Cell Genet. 75 (1996) 7-9.

[29] Fillon V., Morisson M., Zoorob R., Auffray C., Douaire M., Gellin J., Vignal A., Identification of 16 chicken microchromosomes by molecular markers using two-colour Fluorescent In Situ Hybridisation (FISH), Chromosome Res. (1998) in press.

[30] Fritschi S., Stranzinger G., Fluorescent chromosome banding in inbred chicken: quinacrine bands, sequential chromomycin and DAPI bands, Theor. Appl. Genet. 71 (1985) 408-412.

[31] Girard-Santosuosso O., Bumstead N., Lantier I., Protais J., Colin P., Guillot J.-F., Beaumont C., Malo D., Lantier F., Partial conservation of the mammalian NRAMP1 syntenic group on chicken chromosome 7, Mamm. Genome 8 (1997) $614-616$.

[32] Guillemot F., Kaufman J.F., Skjoedt K., Auffray C., The major histocompatibility complex in the chicken, Trends Genet. 20 (1989) 145-155.

[33] Hu J., Bumstead N., Burke D., Ponce de Leon F.A., Skamene E., Gros P., Malo D., Genetic and physical mapping of the natural resistance-associated macrophage protein 1 (NRAMP1) in chicken, Mamm. Genome 6 (1995) 809-815.

[34] Hughes A.L., Hughes M.K., Small genomes for better flyers, Nature 377 (1995) 391.

[35] Jones C.T., Morrice D.R., Paton I.R., Burt D.W., Gene homologs on human chromosome 15q21-q26 and a chicken microchromosome identify a new conserved segment, Mamm. Genome 8 (1997) 436-440. 
[36] Kaback D.B., Chromosome-size dependent control of meiotic recombination in humans, Nature Genet. 13 (1996) 20-21.

[37] Kaelbling M., Fechheimer N.S., Synaptonemal complexes and the chromosome complement of domestic fowl, Gallus domesticus, Cytogenet. Cell Genet. 35 (1983) 87-92.

[38] Khatib H., Genislav E., Crittenden L.B., Bumstead N., Soller M., Sequencetagged microsatellite sites as markers in chicken reference and ressource populations, Anim. Genet. 24 (1993) 355-362.

[39] King M., Honeycutt R., Contreras N., Chromosomal repatterning in crocodiles: C, G and N-banding and the in situ hybridization of $18 \mathrm{~S}$ and $26 \mathrm{~S}$ rRNA cistrons, Genetica 70 (1986) 191-201.

[40] Klein S., Morrice D.R., Sang H., Crittenden L.B., Burt D.W., Genetic and physical mapping of the chicken IGF1 gene to chromosome 1 and conservation of synteny with other vertebrate genomes, J. Hered. 87 (1996) 10-14.

[41] Krishan A., Microchromosomes in the spermatogenesis of the domestic turkey, Exp. Cell Res. 33 (1964) 1-7.

[42] Ladjali K., Tixier-Boichard M., Cribiu E.P., High resolution chromosome preparations for G- and R-banding in Gallus domesticus, J. Hered. 86 (1995) 136-139.

[43] Mariani P., Crittenden L.B., Cheng H.H., Wain H.M., Vignal A., Bumstead N., Current state of the genetic map of the chicken, Anim. Genet. 27 (suppl. 2) (1996) 67.

[44] Matthey R., Caryotype de mammifères et d'oiseaux, la question des microchromosomes, quelques réflexions sur l'évolution chromosomique, Archiv. Genet. 48 (1975) 12-26.

[45] Matzke M.A., Varga F., Berger H., Schernthaner J., Schweizer D., Mayr B., Matzke A.J.M., A 41-42 bp tandemly repeated sequence isolated from nuclear envelopes of chicken erythrocytes is located predominantly on microchromosomes, Chromosoma 99 (1990) 131-137.

[46] Matzke A.J.M., Varga F., Gruendler P., Unfried I., Berger H., Mayr B., Mateke M.A., Characterization of a new repetitive sequence that is enriched on microchromosomes of turkey, Chromosoma 102 (1992) 9-14.

[47] McQueen H.A., Fantes J., Cross S.H., Clark V.H., Archibald A.L., Bird A.PL., CpG islands of chicken are concentrated on microchromosomes, Nat. Genet. 12 (1996) 321-324.

[48] Mengden G.A., Stock A.D., Chromosomal evolution in Serpentes; a comparison of $\mathrm{G}$ and $\mathrm{C}$ chromosome banding patterns of some Colubrid and Boid genera, Chromosoma 79 (1980) 53-64.

[49] Meyne J., Ratliff R.L., Moyzis R.K., Conservation of the human telomere sequence (TTAGGG)n among vertebrates, Proc. Natl. Acad. Sci. USA 86 (1989) $7049-7053$.

[50] Meyne J., Baker R.J., Hobart H.H., Hsu T.C., Ryder O.A., Ward O.G., Wiley J.E., Wurster-Hill D.H., Yates T.L., Moyzis R.K., Distribution of nontelomeric sites of the (TTAGGG)n telomeric sequence in vertebrate chromosomes, Chromosoma 99 (1990) 3-10.

[51] Miller M.M., Goto R., Bernot A., Zoorob R., Auffray C., Bumstead N., Briles W.E., Two Mhc class I and two Mhc class II genes map to the chicken $R f p-Y$ system outside the $B$ complex, Proc. Natl. Acad. Sci. USA 91 (1994) 4397-4401.

[52] Miller M.M., Goto R.M., Taylor R.L., Zoorob R., Auffray C., Briles R.W., Briles W.E., Bloom S., Assignment of $R f p-Y$ to the chicken B microchromosome and evidence for high frequency recombination associated with the nucleolar organizer region, Proc. Natl. Acad. Sci. USA 93 (1996) 3958-3962. 
[53] Moran C., Microsatellite repeats in pig (Sus domestica) and chicken (Gallus domesticus) genomes, J. Hered. 84 (1993) 274-280.

[54] Morescalchi A., Olmo E., Stingo V., Trends of karyological evolution in Pelobatoid frogs, Experentia 33 (1977) 1577-1578.

[55] Morescalchi A., Odierna G., Olmo E., Karyology of the primitive salamenders, family Hynobiidae, Experentia 35 (1979) 1434-1436.

[56] Nanda I., Schmid M., Localization of the telomeric (TTAGGG)n sequence in chicken (Gallus domesticus) chromosomes, Cytogenet. Cell Genet. 65 (1994) 190-193.

[57] Newcomer E.H., The mitotic chromosomes of the domestic fowl, J. Hered. 48 (1957) 227-234.

[58] Ohno S., Sex chromosomes and microchromosomes of Gallus domesticus, Chromosoma 11 (1961) 484-498.

[59] Ohno S., Muramoto J., Stenius C., Christian L., Kittrel W.A., Microchromosomes in Holocephalian, Chondrostean and Holostean fishes, Chromosoma 26 (1969) 35-40.

[60] Pitel F., Fillon V., Heimel C., Le Fur N., El Khadir-Mounier C., Douaire M., Gellin J., Vignal A., Mapping of FASN and ACACA on two chicken microchromosomes disrupts the human 17q syntenic group well conserved in mammals, Mamm. Genome (1998) in press.

[61] Pollock B.J., Fechheimer N.S., Variable C-banding patterns and a proposed C-band karyotype in Gallus domesticus, Genetica 54 (1981) 273-279.

[62] Ponce de Leon F.A., Burt D., Physical map of the chicken: an update, in: Etches R.J., Gibbins A.M.V. (Eds.), Manipulation of the Avian Genome, CRC press, Guelph, Canada, 1993.

[63] Ponce de Leon F.A., Li Y., Weng Z., Early and late replicative chromosomal banding patterns of Gallus domesticus, J. Hered. 83 (1992) 36-42.

[64] Porter C.A., Haiduk M.W., de Queiroz K., Evolution and phylogenetic significance of ribosomal gene location in chromosomes of Squamate Reptiles, Copeia 2 (1994) 302-313.

[65] Primmer C.R., Raudsepp T., Chowdhary B.P., Moller A.P., Ellegren H., Low frequency of microsatellites in the avian genome, Genome Res. 7 (1997) $471-482$.

[66] Rahn M.I., Solari A.J., Recombination nodules in the oocytes of the chicken, Gallus domesticus, Cytogenet. Cell Genet. 43 (1986) 187-193.

[67] Riegert P., Andersen R., Bumstead N., Döhring C., Dominguez-Steglich M., Engberg J., Salomonsen J., Schmid M., Schwager J., Skjodt K., Kaufman J., The chicken $\beta 2$-microglobulin gene is located on a non-major histocompatibility complex microchromosome: a small, $\mathrm{G}+\mathrm{C}$-rich gene with $\mathrm{X}$ and $\mathrm{Y}$ boxes in the promoter, Proc. Natl. Acad. Sci. USA 93 (1996) 1243-1248.

[68] Rodionov A.V., Micro versus macro: a review of structure and functions of avian micro- and macrochromosomes, Russ. J. Genet. 32 (1996) 517-527.

[69] Rodionov A.V., Myakoshina Y.U., Chelysheva L.A., Solovei I.V., Gaginskaya E.P., Chiasmata on lampbrush chromosomes of Gallus gallus domesticus. Cytogenetic investigations of recombination frequency and linkage group length, Genetika 28 (1992) 53-63.

[70] Rodionov A.V., Chelysheva L.A., Solovei I.V., Miakoshina Y.U., Chiasma distribution in the lampbrush chromosomes of the chicken Gallus gallus domesticus: hot spots of recombination and their possible role in proper dysjunction of homologous chromosomes at the first meiotic division, Genetika 28 (1992) 151-160. 
[71] Schmid M., Enderle E., Schindler D., Schempp W., Chromosome banding and DNA replication patterns in bird karyotypes, Cytogenet. Cell Genet. 52 (1989) $139-146$.

[72] Shaw E.M., Shoffner R.N., Foster D.N., Guise K.S., Mapping of the growth hormone gene by in situ hybridization to chicken chromosome 1, J. Hered. 82 (1991) 505-508.

[73] Slizynski B.M., Cytological observations on a duck hybrid: Anas clypeata $\times$ Anas penelope, Genet. Res. Camb. 5 (1964) 441-447.

[74] Stefos K., Arrighi F.E., Repetitive DNA of Gallus domesticus and its cytological locations, Exp. Cell Res. 83 (1974) 9-14.

[75] Stingo V., Rocco L., Odierna G., Bellitti M., NOR and heterochromatin analysis in two cartilaginous fishes by $\mathrm{C}-, \mathrm{Ag}$ - and $\mathrm{RE}$ (restriction endonuclease)banding, Cytogenet. Cell Genet. 71 (1995) 228-234.

[76] Stock A.D., Mengden G.A., Chromosome banding pattern conservatism in birds and non-homology of chromosome banding pattern between birds, turtles and amphibians, Chromosoma 50 (1975) 69-77.

[77] Tegelström H., Ryttman H., Chromosomes in birds (Aves): evolutionary implications of macro- and microchromosome numbers and lengths, Hereditas 94 (1981) 225-233.

[78] Van Brink J.M., L'expression morphologique de la digamétie chez les Sauropsidés et les Monotrèmes, Chromosoma 10 (1959) 1-72.

[79] Wrigley J.M., Marshall Graves J.A., Karyotypic conservation in the mammalian order monotrema (subclass Prototheria), Chromosoma 96 (1988) 231-247.

[80] Zoorob R., Billault A., Severac V., Fillon V., Vignal A., Auffray C., Two chicken genomic libraries in the PAC and BAC cloning systems: organization and characterization, Anim. Genet. 27 (suppl. 2) (1996) 69. 